\title{
Balancing the Needs of the Patient and the Needs of the System
}

Rob Graham, R.R.T./N.R.C.P.

I dedicate this column to the late Dr. Andrew (Andy) Shennan, the founder of the perinatal program at Women's College Hospital (now at Sunnybrook Health Sciences Centre). To my teacher, my mentor and the man I owe my career as it is to, thank you. You have earned your place where there are no hospitals and no NICUs, where all the babies do is laugh and giggle and sleep.

I learned to drive long ago. The process began with me sitting on my maternal grandfather's knee behind the wheel of a half-ton truck or his '58 Oldsmobile. This progressed to the mowing down small trees in a vacant field in my uncle's jalopy, then driving a tractor pulling a hay wagon on my grandmother's farm at age 9. When 16 finally arrived, I took driver's while education in a '73 Oldsmobile Cutlass.

Our family had two vehicles: a '66 Ford 1/2 ton, and a '67 Meteor Rideau 500. (Note to car buffs: Meteor was the Canadian brand of Mercury). The truck had the standard "3 on the tree" transmission, and the other was an automatic. No one was permitted to drive the automatic until they had mastered the standard. This was no small feat! If the shift between first gear to second was precisely done, the entire transmission would lock up, bringing the truck to a screeching stop. What, you may be asking about now, does this have to do with the subject at hand. There are, it seems, a few parallels.

\section{"If the shift between first gear to second was precisely done, the entire transmission would lock up, bringing the truck to a screeching stop. What, you may be asking about now, does this have to do with the subject at hand. There are, it seems, a few parallels."}

Technology has improved the care and outcomes of all patients, be they young or old. Graphics give us information about lung compliance and over-distention; transilluminators make finding and cannulating veins and arteries easier; fiber-optic laryngoscopes provide brighter light, and fiber optic laryngoscopes aid in the visualisation of the airway and placement of the endotracheal tube. There are many more aids and adjuncts available to modern clinicians that were not available when many of us were training.

These and other devices constitute a double-edged sword. In the adult world, "old school" anesthetists complain the skill of laryngoscopy is quickly becoming a lost art. With the relatively recent availability of video laryngoscopy devices in the N.I.C.U., there is fear the same may happen in the world of neonatology. This fear is justified, although experience with the video laryngoscope recently purchased for teaching purposes by the unit in which I work has demonstrated that new devices also have a learning curve. Just how steep that learning curve is, and whether video laryngoscopy becomes standard practice in the N.I.C.U., remains to be seen.

\section{"With fewer and fewer babies being intubated for invasive ventilation or even resuscitation, and the advent of "minimally invasive" surfactant administration, there are fewer and fewer opportunities for trainees to learn this very basic yet essential skill."}

With fewer and fewer babies being intubated for invasive ventilation or even resuscitation, and the advent of "minimally invasive" surfactant administration, there are fewer and fewer opportunities for trainees to learn this very basic yet essential skill. Even babies born with meconium are now rarely intubated.

In many NICUs, respiratory therapists (RRTs) are the ones doing most of the intubations; thus, RRT trainees are also in the training queue. This would not be such a problem were it not for the fact that many of our fellows in training will never again work in a level 3 or 4 facility, but rather a level 2 facility or even a hospital with only a well-baby unit. Why does this present a problem?

In a world experiencing increasingly shrinking health care budgets, it is unlikely that a facility without higher-level neonatal care will invest in the technology we find commonplace in our level 3 and 4 units. Should a patient in one of these facilities require intubation, the ability of the clinician to perform this procedure, "the old-fashioned way" is essential. That clinician may be the only person with neonatal intubation skills available. As well, there are

NEONATOLOGY TODAY is interested in publishing manuscripts from Neonatologists, Fellows, NNPs and those involved in caring for neonates on case studies, research results, hospital news, meeting announcements, and other pertinent topics.

Please submit your manuscript to: LomaLindaPublishingCompany@gmail.com 
facilities that do not have in-house anesthesia overnight. Similarly, there is likely a dearth of other technological aids; ultrasound, for instance, available for inserting intravenous, arterial, or umbilical lines. Ventilators may be limited to "jack of all" machines primarily used for adult ventilation but with pediatric and neonatal functionality.

What we take for granted is simply not widely available in lower functioning facilities. In addition, many foreign trainees return to their home countries and facilities, where the level of technological assistance available to us in the "first world" may be non-existent. The problem is obvious. Without learning basic skills, the training we provide for these future neonatologists is incomplete.

Simulations and simulators offer some mitigation, but as anyone who has intubated a mannequin can attest to, they are not a perfect substitute for the real thing. Anatomical anomalies, secretions, and extremely anterior airways are common challenges that a mannequin is unable (to the best of my knowledge) to duplicate. This should not be construed as an "anti-sim" opinion piece. As in the field of aviation, simulations hold great promise in medical training. They are a safe place to make mistakes, practice judgment, and decision-making skills, and offer a degree of skill development. Perhaps it is neonatology that poses a bigger challenge to simulations. There are situations that cannot be adequately taught in a simulation setting.

\section{"Perhaps it is neonatology that poses a bigger challenge to simulations. There are situations that cannot be adequately taught in a simulation setting."}

Simulators ranging from 25-weeks ("micro-preemie") are available. These offer a chance to practice oral intubation, umbilical line placement, IV placement, nasogastric tube placement, and can present a variety of birth defects. To the best of my knowledge, these devices do not offer experience with false-tracking umbilical lines or femoral artery or hepatic catheterisation. There are clinical signs of these occurrences in real life that a simulator can't simulate. These devices are a great start, but they are not a true substitute for a real patient, nor are they a complete substitute for clinical practice.

This is of concern as simulation sessions become an increasingly large part of basic training and substitution for real-life experience for trainees. Anecdotally, there is a subtle difference observed in students with extensive simulator training; however, literature does not support these observations ${ }^{1}$. It is worth noting that the amount of clinical time replaced by simulation in this study was limited to $50 \%$. While there was no difference in pass rates or educational outcomes, passing does not always equate to real-world competence. Every trainee I have worked with has passed their didactic and clinical programs. The real test might be how many of the simulator group actually pass orientation in a critical care setting. It is also interesting that there is some evidence that higherfidelity simulations do not necessarily improve learning objectives, including neonatal resuscitation program learning. ${ }^{3}$

As real as simulations are, there is no substitute for the adrena- line-fueled panic that can ensue in real life (although I have witnessed just that during simulations). There is no "time out" function in the resuscitation room. Simulators do offer opportunities to experience a variety of clinical situations that a trainee may never see during a typical rotation. ${ }^{2}$ Whatever one's personal views are, it is undeniable that simulation training has become an integral part of medical education and is here to stay.

I recall attending a lab session during my training, where we practiced intubating anesthetized cats. I learned two things: cats are easy to intubate, and cats are not babies. While in my adult training program, we were also encouraged, where possible, to practice laryngoscopy on cadavers post unsuccessful resuscitation to improve competency. The ethics of doing this today may be called into question, but the experience gained cannot be disputed.

The micro-premature infant presents another quandary. It is generally accepted where I practice that the most experienced person present at resuscitation is the one who manages the airway. Compounding the problem in the unit in which I practice is we intubate nasally wherever and whenever possible. I have yet to find a mannequin that allows for nasal endotracheal tube placement. How then are trainees to learn these skills? Clearly, when it comes to patient care, we want what is best for our babies, and the needs of trainees are secondary. The question here is, how does this philosophy serve future patients and those destined to be treated by those trainees? Where is the balance? What are the ethical implications? Perhaps it is time that we, as practitioners, should be addressing these issues to improve training as a whole.

Perhaps the same technology creating these problems will, with evolution and innovation, create needed solutions. Some higherend mannequins have anatomy with a range of adjustments (the size of the palate, for instance). While I have faith in the ability of technology to save us from technology, it comes with a price and a very high one at that. The cost of furnishing a complete simulation suite is steep. The question of whether cash strapped institutions will be amenable to this investment remains. Until that time, we must make do with what is available to us as teachers.

\section{"The one place where endotracheal intubation is still commonplace is the operating room. This could be the ideal venue for learning laryngoscopy and intubation in a controlled environment and under the watchful eyes of a skilled, experienced pediatric anesthetist."}

The one place where endotracheal intubation is still commonplace is the operating room. This could be the ideal venue for learning laryngoscopy and intubation in a controlled environment and under the watchful eyes of a skilled, experienced pediatric anesthetist. This would require liaising with our anesthesia colleagues but could also have an impact on the training of new anesthetists who also must have excellent intubation skills. There are only so many trainee vacancies on their roster and only so many patients for neonatology trainees on whom to practice. Therefore, the limited opportunity the N.I.C.U. affords trainees to learn intubation skills 
could, at present, leave us with no choice but simulation.

Finally, I believe that neonatal fellowship programs should offer a respiratory rotation. While RRTs are the primary drivers of ventilation in some units, outside North America, this is a profession that does not exist. When foreign trainees return to their native lands, it is they who must run the ventilators. Who better to learn the intricacies of ventilators and mechanical ventilation from than those who have made it their life's work? A four-week rotation acting as an RRT orientee could prove invaluable, especially to our foreign trainees.

To use the driving analogy, we all should learn standard before availing ourselves of the luxury of an automatic. By the way, to this day, my vehicles have standard transmissions. I also intubate the "standard" way. When Armageddon comes, I will be doing it the "old fashioned way." How about you?

\section{Referenes:}

1 https://ojin.nursingworld.org/MainMenuCategories/ANAMarketplace/ANAPeriodicals/OJIN/TableofContents/ Vol-23-2018/No2-May-2018/Articles-Previous-Topics/ Simulation-Based-Learning-Undergraduate-Education. html\#: : text=The $\% 20$ control\%20group $\% 20$ could $\% 20$ have,who\%20had\%20more\%20clinical\%20time.

2 https://www.ncbi.nlm.nih.gov/pmc/articles/PMC3195067/

3 https://www.sciencedirect.com/science/article/piil $\underline{\text { S1658361215000141 }}$

Disclosures: The author receives compensation from Bunnell Inc for teaching and training users of the LifePulse HFJV in Canada. He is not involved in sales or marketing of the device nor does he receive more than per diem compensation. Also, while the author practices within Sunnybrook H.S.C. this paper should not be construed as Sunnybrook policy per se. This article contains elements considered "off label" as well as maneuvers, which may sometimes be very effective but come with inherent risks. As with any therapy, the riskbenefit ratio must be carefully considered before they are initiated.

NT

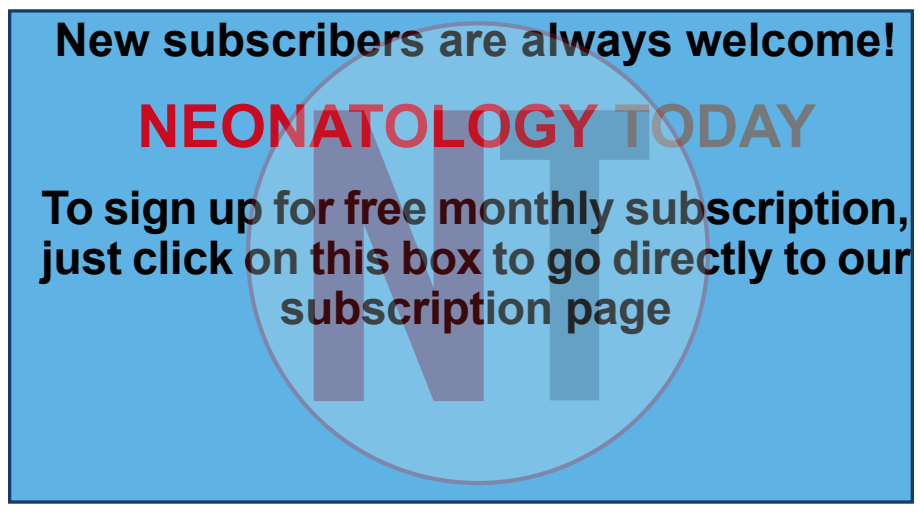

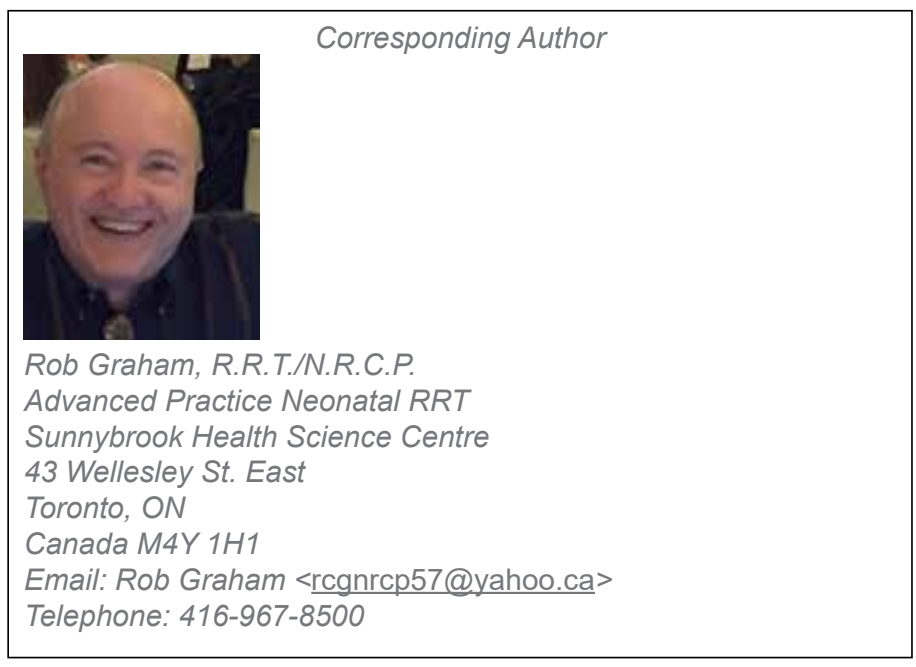

\section{Readers can also follow EONATOLOGY TO via our Twitter Feed @NEOTODAY}

\section{NICU AWARENESS MONTH}

EACH YEAR
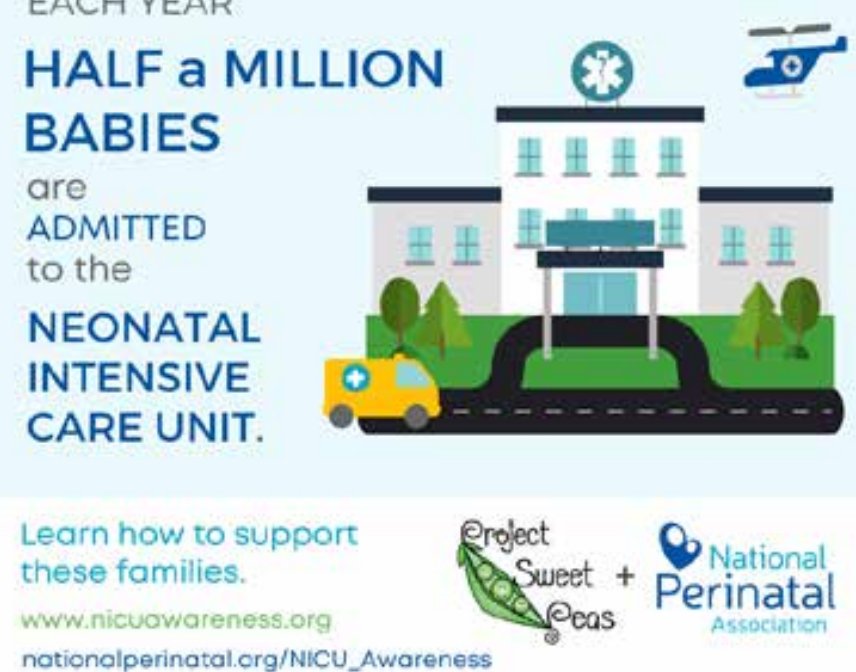

notionalperinatal.org/NiCU_Awareness

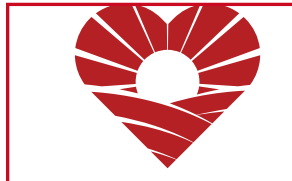

CONGENITAL CARDIOLOGY TODAY
The only worldwide monthly publication exclusively serving Pediatric and Adult Cardiologists that focus on Congenital/ Structural Heart Disease (CHD), and Cardiothoracic Surgeons.

\section{Subscribe Electronically}

Free on the Home Page

www.CongenitalCardiologyToday.com 